\title{
Introduction to HICSS-54 Minitrack on Digital and Social Media in Enterprise
}

\author{
Xuefei (Nancy) Deng \\ California State University \\ Dominguez Hills \\ ndeng@csudh.edu
}

\author{
Ester S. Gonzalez \\ California State University \\ Fullerton \\ esgonzalez@fullerton.edu
}

\author{
Tawei (David) Wang \\ DePaul University \\ david.wang@depaul.edu
}

\section{Introduction}

Digital and social media (DSM) have transformed the workplace in organizations. Two decades ago, the use of electronic communication technologies--such as emails, messaging, and teleconference systems-promoted effective electronic communications in organizations. Electronic communication changed organizational forms, enabled electronic document management, and preserved organizational memory. Currently, the growth of digital and social media technologies are impacting organizations in new ways. Social media includes blogs, wikis, social networking sites, and microblogging that provide new affordances to its users. While some prior studies have provided evidence to show the positive impacts of enterprise social media on employees, work processes and performance, other studies have uncovered negative effects of DSM use on employee productivity and behaviors. For an organization to amplify the returns or benefits and to mitigate the drawbacks of their DSM use, it is imperative for both researchers and practitioners to deepen their understanding of the implications of DSM use for organizational purposes.

\section{Scope}

This minitrack focuses on the internal and external use of digital and social media by organizations to facilitate work processes (e.g., communication, collaboration, innovation and socialization) inclusive of business, non-profit organizations, and government agencies. Hence, research of this minitrack lies at the intersectionality of multiple disciplines, namely Science \& Technology, Organization Science, Marketing, and Behavioral Science.

This minitrack presents both theoretical and empirical studies addressing organizational, managerial, technical, and behavioral perspectives on digital and social media in enterprises.
Potential issues and topics include, but are not limited to:

- Digital and social media affordances

- Digitization of work and its impact on work process

- Digital platform and work/job design

- Digital and social media use \& electronic document management

- Digital and social media use \& employee work-life balance

- Digital and social media use \& Information security

- Effects (both positive and negative) of digital and social media at workplace

- Methodologies for studying digital and social media in enterprise

- Organizational management practices associated with digital and social media use

- Organizational policies on digital and social media use

- New theories to describe and explain the phenomenon of using digital and social media in workplace

- Organizational memory in the era of social and digital technologies

- Roles and responsibilities of IS departments in the use of and support for digital and social media

- The use of social media \& fundraising or donations

- The use of social media \& public perception management

- The use of social media \& enterprise strategy

\section{Summary of Articles}

This mini-track presents four papers in HICSS54. We introduce them briefly below.

While enterprise social media (ESM) can benefit organizational operation and performance by 
enhancing organizational communication, employee collaboration and productivity, it can also cause stress among employees. As such, it's important to investigate the stressors that arise from ESM use. Högberg [1] addresses this important question in the paper titled "Technostress and Social Media at Work - Investigating Negative and Positive Stressors and Strains from a Person-Technology-Fit Perspective." The study examines both negative and positive stressors and strains deriving from using multiple social media in an international hotel chain with employees in eight European countries over a period of seven years. While the study shows that techno stressors such as work overload, work-life conflict, and changing algorithms create negative stressors, it also reveals that positive stressors such as the ability to create new ways of providing service. By suggesting a development of the Person-Technology fit model as well as uncovering both positive and negative stressors and strains created over time, the study contributes to the technostress research in the Information Systems field.

Adopting a different perspective from Högberg [1], Estell, Davidson and Abhari [2] intend to understand how ESM use to engage employees and facilitate employee voicing behaviors within organizations in their paper titled "Affording Employee Voice: How Enterprise Social Networking Sites (ESNS) Create New Pathways for Employee Expression." In this paper, they develop the concept of ESNS voicing affordances that enable employees to individually and directly express their voice within their organizations. The authors establish an instrument for the construct of ESNS voicing affordances by reviewing relevant literature on employee voice and social media affordances and following a systematic scale development process. The developed construct of ESNS voicing affordances consist of three distinctive, formative dimensions - promotive, prohibitive, and advocacyand 12 validated items. Findings of this study offer useful practical guidance for organizations to capitalize on social technologies to find new ways to promote employee voicing behavior and increase employee workplace participation.

At the firm level, international businesses can use social media to increase their knowledge of customers and enhance their provision of products and services. Yet our knowledge about how the SM use ambidextrous learning and foreign market entry survival remains limited. In the paper titled "Ambidextrous Learning and Survival of Early International Firms-The Role of Social Media Usage," Appiah [3] draws upon research on international entrepreneurship (IE), information systems, and ambidexterity to examine SM use by firms in the international business context. Adopting the theoretical framework of organizational learning (i.e. exploratory learning and exploitative learning), the study proposes that SM usage for marketing, building customer relations and information accessibility positively influences ambidextrous learning, and enhances the survival of international new ventures. The paper contributes to SM and IE research by providing a conceptual explanation of the underlying mechanisms by which the phenomenon of SM drives ambidextrous learning and survival.

Finally, Wu, Chen, and Chiang [4] examine the relationship between live-streaming format and its impacts of viewing behavior in their paper titled "Forming the Strategy for Live Streaming ECommerce: An Action Research." The study adopts a participatory action research method and develops the live streaming effectiveness framework. Informed by a consumer behavior model, the AISAS (attention, interest, search, action, and share) Model, the study decomposes the live streaming program into four features (topic, film length, celebrity, and place) and tests the effect of the features by using data collected from 128 live streams data in a 30-day period. The ANOVA results confirms the effect of celebrity, but the study points out the need for celebrities to have sufficient knowledge and experience to host the live streaming. The study also highlights the benefit for managers and marketers to increase the attention and interest of the viewers.

The presentations of the four papers cover a wide variety of topics - including ESM use, techstress, employee voicing, customer (or viewer) behaviors, firm performance and survival - that are examined in diverse context ranging from for-profit companies to international new ventures.

\section{Reference}

[1] Högberg, K. "Technostress and Social Media at Work - Investigating Negative and Positive Stressors and Strains from a Person-Technology-Fit Perspective," in HICSS-54 Proceedings, January 5-8, 2021, Hawaii.

[2] Estell, P., E. Davidson and K. Abhari. "Affording Employee Voice: How Enterprise Social Networking Sites (ESNS) Create New Pathways for Employee Expression," in HICSS-54 Proceedings, January 5-8, 2021, Hawaii.

[3] Appiah, E. K. "Ambidextrous Learning and Survival of Early International Firms-The Role of Social Media Usage," in HICSS-54 Proceedings, January 5-8, 2021, Hawaii.

[4] Wu, C. C., C. J. Chen, and T. W. Chiang, "Forming the Strategy for Live Streaming e-Commerce: An Action Research," in HICSS-54 Proceedings, January 5-8, 2021, Hawaii. 